\title{
The practical application of biomechanical theory for patient assessment
}

\author{
Trevor D Prior \\ From Australasian Podiatry Council Conference 2011 \\ Melbourne, Australia. 26-29 April 2011
}

Podiatric biomechanical assessment has become a fundamental cornerstone of podiatric practice. However, whilst there are many papers indicating the positive benefits of orthotic intervention, the underlying assessment philosophies remain controversial. The work produced by Root, Orien and Weed still underpins much of the current assessment and management techniques, yet key aspects of their concepts are not supported by scientific scrutiny. For every paper that seems to support aspects of function, there are more which do not support common theory. As a result, several conceptual assessment techniques have been developed and expounded although the evidence base to support these theories remains weak at best. This leaves the clinician who wishes to practice evidenced based medicine in a dilemma when presented with a patient in discomfort. To date, there has been little evidence to guide such an approach and thus replace the disproved theory. This workshop will review common assessment techniques and factors which effect limb function. It will outline an approach which can be taken to integrate these techniques and provide a basis for care utilising the current evidence available. This will include a practical demonstration of assessment techniques.

Published: 20 May 2011

doi:10.1186/1757-1146-4-S1-19

Cite this article as: Prior: The practical application of biomechanical

theory for patient assessment. Journal of Foot and Ankle Research 2011 4(Suppl 1):19.

Correspondence: Trevor.prior@premierpodiatry.com
Homerton University Hospital, London, E9 6SR, UK

Submit your next manuscript to BioMed Central and take full advantage of:

- Convenient online submission

- Thorough peer review

- No space constraints or color figure charges

- Immediate publication on acceptance

- Inclusion in PubMed, CAS, Scopus and Google Scholar

- Research which is freely available for redistribution 